\title{
Recent Progress and Future Challenges of Functional Textiles Fabricated by Atomic Layer Deposition
}

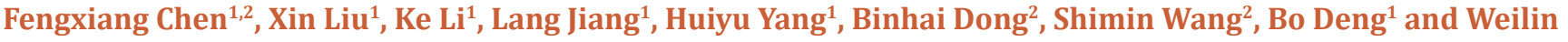 \\ $\mathrm{Xu}^{1 *}$ \\ ${ }^{1}$ State Key Laboratory of New Textile Materials \& Advanced Processing Technologies and Hubei Key Laboratory of Advanced Textile Materials \& \\ Application and School of Material Science and Engineering, Wuhan Textile University, China \\ ${ }^{2}$ Hubei Collaborative Innovation Center for Advanced Organic Chemical Materials and Ministry of Education Key Laboratory for the Green Preparation \\ and Application of Functional Materials, Hubei University, Wuhan, China
}

Submission: October 02, 2017; Published: November 14, 2017

*Corresponding author: Bo Deng, State Key Laboratory of New Textile Materials \& Advanced Processing Technologies and School of Material Science and Engineering, Wuhan Textile University, Wuhan, Hubei 430200, China, Email: dengjianguo88@outlook.com

Weilin Xu, State Key Laboratory of New Textile Materials \& Advanced Processing Technologies and Hubei Key Laboratory of Advanced Textile Materials, Wuhan Textile University, Wuhan, Hubei 430200, China, Email: weilin-xu@hotmail.com

\begin{abstract}
Atomic Layer Deposition (ALD) technique has been regarded as one of the most efficient and promising approaches for the functionalization of complex-shaped surfaces due to its precise and simple thickness control, excellent conformality. Additionally, mild growth conditions such as low temperature and oxygen-free characteristic of ALD made it particularly attracting for the fabrication of functional textiles. Functionalization of natural or synthetic fabrics such as cotton, silk, polyvinyl alcohol, Kevlar and even to chemical-inert Carbon Fiber (CFF) via ALD to endow them with super hydrophobicity, conductivity, antibacterial activity, UV-blocking property, anti-yellowing property, and retardancy are reviewed. Finally, the challenges and perspectives on the application of ALD in the functionalization of fabrics are proposed.
\end{abstract}

Keyword: Atomic layer deposition; Functional fabrics; Future challenges

\section{Introduction}

The natural and synthetic fibers have been deeply rooted into our daily life and it is unimaginable that the life without fabrics. Increasing damage caused by exposure to microbes, chemical, pesticide, UV light and pollutants has strengthened the demand for fabrics which are expected to be waterproof [1], flame retardant, antimicrobial [2-3], self-cleaning [1,4-5] and so on. Conventional finishing methods such as pad-dry-cure or coating are widely used to impart desired functions feather to fabrics in industry. While the excessive add-on weight, poor washing stability, weaken mechanical strength and reduced comfort to wearer are eagerly to be solved. Alternatively technologies, which are eco friendly, laundering durable [1], cost effective and do not lower the comfortability while maintaining optimum protection functions are still being eagerly pursued.

Many new functionalization methods and techniques, including enzyme immobilization [6], layer by layer assembling [7], electrophoretic deposition [8], and Atomic Layer Deposition (ALD) [9-13] are utilized to achieve the multi-functionalization of fabrics. Among them, ALD technique has been regarded as one of the most efficient and promising approaches due to its precise thickness control down to atomic level, excellent conformality and capability for deposition onto the complex-shaped surfaces. Additionally, the ALD of metal oxides such as $\mathrm{Al}_{2} \mathrm{O}_{3}, \mathrm{TiO}_{2}$ and $\mathrm{ZnO}$ could even be carried out at low temperature, which render great interest in the surface-modification for temperature-sensitive fabrics.

ALD is realized by repeating cycles of self-limiting gas-solid reactions adhere to self-assembly chemistry. The precursor gases are alternately pulsed into the reactor, and excess gaseous precursors and by-products are removed by an inert purge gas pulse after each half-reaction. For each cycle, only one atomic layer is formed on the surface, enabling tailored thickness down to atomic/molecular level on ideal/complex surface. Desired thickness could be easily achieved by repeating the ALD cycles to a certain number. The advantages in the precisely thickness controlling and resulted excellent conformal thin film made ALD a good candidate for applications in the functionalized fabrics [14].

Hence, a review covers both of the growth mechanism and applications of ALD on fiber/fabrics is necessary to clarify their 
recent progress. In this review, the general description of ALD growth mechanism was firstly introduced briefly. Then the extended mechanism is proposed to understand the surface growth mechanism of ALD on fiber/fabrics. Finally, the future challenges of applications in ALD-modified functional fabrics is presented.

\section{ALD Fundamentals}

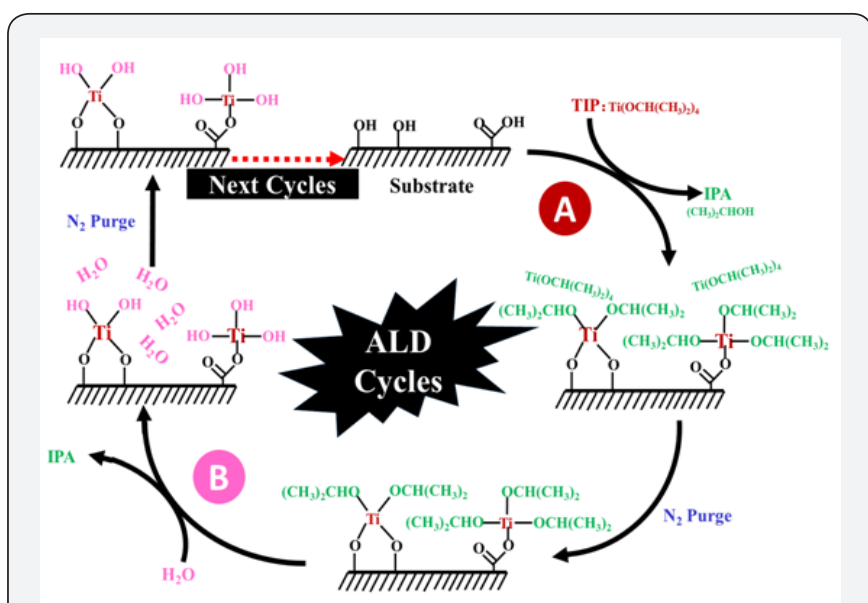

Figure 1: The chemical reaction mechanism of $A L D \mathrm{TiO}_{2}$ onto fabrics.

Figure 1 depicted the typical reaction mechanism of the low-temperature ALD process with Titanium (IV) IsoPropoxide (TIP)/water $\left(\mathrm{H}_{2} \mathrm{O}\right)$ for ALD deposition of $\mathrm{TiO}_{2}$ onto fiber/fabrics. Firstly, the TIP moleculars were pulsed and adsorbed onto the substrate surface and react with active hydroxyl group or carboxyl group to form a monolayer $\mathrm{TiO}_{2}$ layer. By-products and unreacted precursor were purged out by followed pulse of highpurity nitrogen $\left(\mathrm{N}_{2}\right)$. By repeating above-mentioned cycle to certain numbers, the $\mathrm{TiO}_{2}$ layers with desired coating thickness are obtained, indicating that the growth mode is generally close to $2 \mathrm{D}$ mode.

In fact, one ALD cycle consists of two time-separated half reactions. In the first half reaction, the substrate is exposed to TIP vapor that forms a sub-monolayer films of the precursor on the surface of the substrate, followed by the use of a purge gas to remove the excess TIP precursor. In the second half reaction, the subsequently pulsed reactant gas reacts with the as-adsorbed precursor layer to form a target film. After such cycle, only one TiO2 molecular layer is deposited onto the surface of the substrate.

\section{Applications of ALD technique in the functionalization of fabrics}

Different with the surfaces of inorganic solids such as silicon wafer, woven and nonwoven fabrics normally made from natural or synthetic polymer suffered from the lacking of surface-bound active groups such as hydroxyl groups which are indispensable to initiate the ALD reaction. This makes the woven and nonwoven fabrics to adopt a very different growth mechanism. Firstly, the first reaction between precursor and polymeric fabric surface always accompanied by a precursor molecular penetrating process. In this case, several different kinds of chemical bonds will form between the inorganic nanoparticles layer and polymeric fabrics compared with that on inorganic solid surface. Secondly, numerous inter-chain gaps at different sizes allow the penetration of ALD precursors inside the bulk of fabrics which results in different surface morphology and roughness. Not only the outmost exposed surface but also the interior surface of polymer chains could be deposited. Thirdly, other active groups involved in the polymer frame such as amide, carboxyl, hydroxyl group provide more complicated chemical reactions leading to various reaction products and mechanisms. The reaction mechanisms of ALD onto polymeric fabrics could be classified into two types: (i) polymeric fabrics with abundant surfacebound reactive groups, particularly hydroxyl groups, and (ii) fabrics lacking of surface reactive groups.

\section{Polymeric fabrics with copious reactive groups}

Some fabrics such as cotton, silk, wool, cellulose, polyvinyl alcohol, polyamide are kind of fabrics with abundant surfacebound active groups including $-\mathrm{OH},-\mathrm{COOH},-\mathrm{NH}_{2}$, which are widely accepted as effective groups to form covalent bond with ALD inorganic layers ( $\mathrm{ZnO}, \mathrm{TiO}_{2}, \mathrm{Al}_{2} \mathrm{O}_{3}$ and so on). The multiple functions properties, such as antibiosis, UV-blocking [15], antioxidation [16-18], superhydrophobicity $[13,19]$, conductivity [11,20-31], and retardancy [32,33] could be endowed to polymeric fabrics after ALD of different inorganic layers onto their surface.

Regulating wettability of fabrics by ALD: The desire for fabrics with self-cleaning property provides strong motivation to the research on how to regulate surface wettability via ALD. The wettability of water on textured surfaces depends on both the surface topography (tightly linked with surface roughness) and the surface energy of the fabric. By selected exposing outmost function group after ALD, the surface can be switched between hydrophobic and hydrophilic. Upon coating by $\mathrm{ALD} \mathrm{Al}_{2} \mathrm{O}_{3}$, nonwetting polypropylene surface was switched to a water wetting state while cotton fabrics surface was switched from a fully wettable state to a strong hydrophobic state for a long time even after one cycle of Tri Methyl Aluminum (TMA) deposition. This difference was attributed to the more stable $\mathrm{Al}-\left(\mathrm{O}-\mathrm{CH}_{3}\right)_{3}$-n groups and few unstable hydrophilic $\mathrm{Al}-\mathrm{OH}$ groups on the outmost surface of cellulose fabric [13]. A carbon absorption after deposition also contributed to this long-lasting hydrophobicity. Another work by Hyde [9] reveals that cotton textiles modified with conformal nanoscale $\mathrm{Al}_{2} \mathrm{O}_{3}$ are found to show extreme hydrophobic effects, distinctly different from planar surfaces that receive the same coatings. This convinced that the extreme hydrophobicity (contact angle increases from 0 to $127^{\circ}$ ) lies on both the low surface energy and the surface roughness. This 
regulation of the surface wettability via ALD was furtherly applied to improve the print quality of wet-laid nonwoven cellulose fabric by coating $\mathrm{TiO}_{2}$ and $\mathrm{Al}_{2} \mathrm{O}_{3}$ layers using titanium tetrachloride $/ \mathrm{H}_{2} \mathrm{O}$ and $\mathrm{TMA} / \mathrm{H}_{2} \mathrm{O}$ as precursors, respectively [24]. To some extremely case, even a superhydrophobic surface with a water contact angle up to $160^{\circ}$ could be successfully constructed on the wool fabric by $\mathrm{ALD} \mathrm{Al}_{2} \mathrm{O}_{3}$ [13].

Conductive coatings on textiles: Conductive fibers are excellent candidates for a broad range of applications, including chemical sensing, energy storage, flexible antennas, and foldable displays. More importantly, metal ALD coatings on fabrics provides solvent-free functionalization of textiles for electronic applications. Sweet [11] tried to improve the conductivity of the nonwoven polypropylene fabric by coating ZnO layer onto their surfaces but it doesn't work. The transmission electron microscopy shows that the conductive $\mathrm{ZnO}$ penetrates into the porous fabric and thus contribute few to the conductivity. Inserting a insulated $\mathrm{ALD} \mathrm{Al}_{2} \mathrm{O}_{3}$ layer prior to the $\mathrm{ZnO}$ growth could effectively block the penetration of the $\mathrm{ZnO}$ gaseous reactants into the fabrics thusly resulted a higher effective conductivity (> $25 \mathrm{Scm}^{-1}$ ) after 200 ALD ZnO cycles. For comparison, ZnO deposition on nonwoven nylon- 6 fabric exhibits uniform growth without $\mathrm{Al}_{2} \mathrm{O}_{3}$ pretreatment and the conductivity again changes significantly with the Al203 pretreatment. Jur et al. [28] also reported the coating of cotton fibers with $\mathrm{ZnO}$ via ALD to introduce the conductivity. The conductivity of coated cotton fibers increases with the increase in coating thickness. Different with using metal oxide coatings, low-temperature vaporphase tungsten Atomic Layer Deposition (ALD) using WF6 and dilute silane $\left(\mathrm{SiH}_{4}, 2 \%\right.$ in Ar) yields highly conductive coatings on nylon-6 micro fiber mats, producing flexible and supple nonwovens with conductivity of $\sim 1000 \mathrm{~S} / \mathrm{cm}$ [29]. Mundy et al. [21] also produce highly conductive nonwoven nylon- 6 fiber mats having effective conductivities as high as 5500-6000 S/cm with only a $6 \%$ fractional increase in mass by low temperature platinum atomic layer deposition via (methylcyclopentadienyl) trimethyl platinum and ozone.

UV-blocking textiles: UV irradiation can cause a severe damage to textiles in terms of color, mechanical strength, and human physiological comfort. Inorganic UV absorbers like ZnO, $\mathrm{SiO}_{2}$, and $\mathrm{TiO}_{2}$ in the micro- or nanoscale are in particularly attractive due to their superior performance. Xiao et al. [15] deposited $\mathrm{TiO}_{2}, \mathrm{Al}_{2} \mathrm{O}_{3}$, and $\mathrm{TiO}_{2} / \mathrm{Al}_{2} \mathrm{O}_{3}$ nano-layer onto dyed polyamide/aramid blend fabric surface. The dyed fabrics after ALD coating showed excellent UV resistance and high resistant to UV-induced mechanical strength damage.

Apart from synthetic polymer fabrics as mentioned above, natural polymer fabrics such as silk fabrics showed much better UV-blocking properties after coated with $\mathrm{TiO}_{2}$ by ALD. The strong absorbance against UV of $\mathrm{TiO}_{2}$ made it a good UV sacrificial absorbent which could significantly protect the silk fiber from
UV-induced yellowing and deterioration in mechanical property [16].

\section{Fabrics lacking of reactive groups-Carbon fibers or fabrics}

Different with polymeric fabrics with copious surfacebound reactive groups, carbon-based fabrics are short of active groups which can't initiate the ALD reaction. While surface pretreatment to carbon fiber fabrics are widely adopted in order to the increase their interface binding force with epoxy. This pretreatment provide the possibility for the ALD by more or less generating some active groups on the surface of carbon fiber fabrics. The amount of these active groups are sufficient to form a dense inorganic layer on the fabrics via ALD. For other fabrics short of surface-bound active groups, plasma treatment under oxygen is a promising method for introducing active groups.

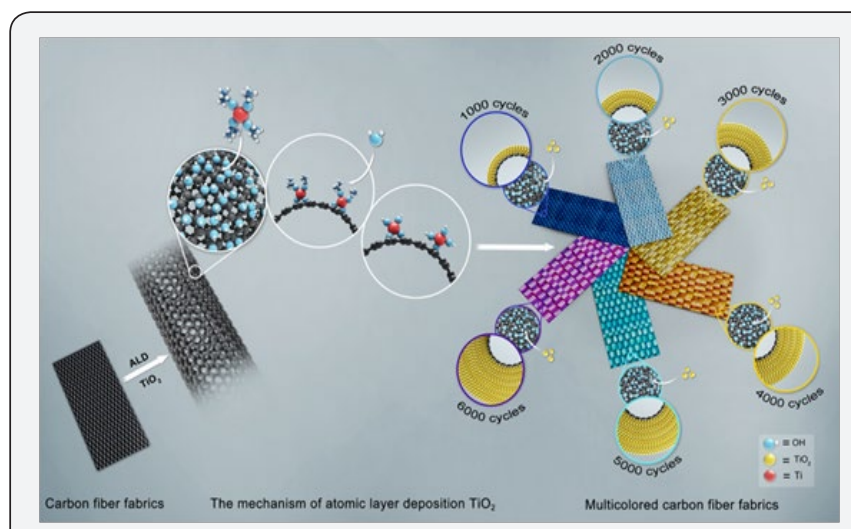

Figure 2: Schematic illustrations of fabrication procedure of multicolored CFFs using the ALD method and the chemical reaction mechanism for deposition of $\mathrm{TiO}_{2}$ layer on CFFs (reprinted with permission from [38]).

Coloration of dye-inert fabrics: As a high-performance fibers, carbon fibers play a very important role in a variety of hightech fields, including aerospace, sports, automotive, chemical industry, infrastructure, military, energy, reinforcement in composite materials, textiles, and semiconductors, owing to their remarkable properties, such as high strength, stiffness, heat and chemical resistance, low densities, good thermal and electrical conductivities, excellent creep resistance, biological compatibility, and fatigue resistance [34-37]. However, coloring of carbon fibers is difficult due to insufficient chemical affinity between carbon fibers and dyes and their high crystallinity. Multicolored carbon fiber fabrics was recently prepared by Chen et al. using ALD, which showing various and vibrant structural colors [38] by controlling the thickness of coated conformal TiO2 layer while only slightly weaken their mechanical properties Figure 2.

Improvement of anti-oxidation property of fabrics: Meanwhile, carbon fibers are sensitive to oxidation and tensile properties will deteriorate strongly when temperatures exceeding $400^{\circ} \mathrm{C}$ in oxidizing humid conditions [39-42]. To 
protect carbon fibers from reaction with oxygen, coating a diffusion barrier made from silica, alumina, titania, etc onto fibers is a successful strategy. Westwood et al. [43], coated alumina onto carbon fibers by ALD via sequential exposed to tri methyl aluminum and water at the low temperature $\left(\sim 77^{\circ} \mathrm{C}\right)$. The starting oxidation temperature of carbon fiber fabrics was significantly increase from $300^{\circ} \mathrm{C}$ (pristine carbon fiber fabrics) to $600{ }^{\circ} \mathrm{C}$ (alumina layer with the thickness of $30 \mathrm{~nm}$ ) and $660{ }^{\circ} \mathrm{C}$ (alumina layer with the thickness of $120 \mathrm{~nm}$ ) respectively.

\section{Challenges and outlooks}

In this review, we summarized the reaction mechanism and surface chemistry of ALD deposition on fabrics as well as the existing functionalizations of natural and synthetic fabrics via ALD. The ability of ALD to regulate the surface energy, reactivity and wettability of polymeric fabrics widens its application in separations, electronic-chemical system, biological scaffolds, energy conversion devices, and flexible chemically active systems.

Despite the achievements made over recent years, many challenges still remain for the future development of ALD in fabrics, such as (i) difficulties in theoretical modeling of the reactions on sophisticated fabric surface, (ii) difficulties in scaling up the ALD to large volume for industry production, (iii) reaching an acceptable process speed. A system and method for continuous atomic layer deposition was patented by Elam [23]. This atmosphere applicable ALD system which can work continuously expands the further application of ALD for the roll-to-roll production of functional fabrics. We believe that all existing researches on ALD modified fabrics would open a new doors in the market for functional fabrics particularly when combined with the well-developed roll-to-roll technology.

\section{Acknowledgement}

This research was financial supported from the National Science Foundation for Distinguished Young Scholars (Grant No. 51325306) and the National Natural Science Foundation of China (Grant No. 51773158). The authors would like to acknowledge the Key Laboratory of Textile Fiber \& Product (Wuhan Textile University) Grant (Project no. FZXW2017013) for support of this project. Fengxiang Chen and Xin Liu contributed equally to this works.

\section{References}

1. Deng B, Cai R, Yu Y, Jiang H, Wang C, et al. (2010) Laundering durability of superhydrophobic cotton fabric. Adv Mater 22(48): 5473-5477.

2. Zhao J, Deng B, Lv M, Li J, Zhang Y, et al. (2013) Graphene oxide-based antibacterial cotton fabrics. Adv Healthc Mater 2(9): 1259-1266.

3. Liu H, Lv M, Deng B, Li J, Yu M, et al. (2014) Laundering durable antibacterial cotton fabrics grafted with pomegranate-shaped polymer wrapped in silver nanoparticle aggregations. Scientific Reports 4(4): 5920-5928.

4. Wu J, Li J, Deng B, Jiang H, Wang Z, et al. (2013) Self-healing of the superhydrophobicity by ironing for the abrasion durable superhydrophobic cotton fabrics. Scientific Reports 3(3): 2951-2957.

5. Gulrajani ML, Gupta D (2011) Emerging techniques for functional finishing of textiles. Indian Journal of Fiber \& Textile Research 36(4): 388-397.

6. Gao Y, Truong YB, Cacioli P, Butler P, Kyratzis IL (2014) Bioremediation of pesticide contaminated water using an organophosphate degrading enzyme immobilized on nonwoven polyester textiles. Enzyme Microb Technol 54: 38-44.

7. Kathirvelu S, D'Souza L, Dhurai B (2009) A study on functional finishing of cotton fabrics using nano-particles of zinc oxide. Materials Science 15(1): 75-79.

8. Liu Z, Zhang Q Wang H, Li Y (2013) Structurally colored carbon fibers with controlled optical properties prepared by a fast and continuous electrophoretic deposition method. Nanoscale 5(15): 6917-6922.

9. Hyde GK, Scarel G, Spagnola JC, Peng Q Lee K, et al. (2010) Atomic layer deposition and abrupt wetting transitions on nonwoven polypropylene and woven cotton fabrics. Langmuir 26(4): 2550-2558.

10. Hyde GK, Park KJ, Stewart SM, Hinestroza JP, Parsons GN (2007) Atomic layer deposition of conformal inorganic nanoscale coatings on threedimensional natural fiber systems: effect of surface topology on film growth characteristics. Langmuir 23(19): 9844-9849.

11. Lii WJS, Jur JS, Parsons GN (2013) Bi-layer $\mathrm{Al}_{2} \mathrm{O}_{3} / \mathrm{ZnO}$ atomic layer deposition for controllable conductive coatings on polypropylene nonwoven fiber mats. Journal of Applied Physics 113(19): 1415.

12. Brozena AH, Oldham CJ, Parsons GN (2016) Atomic layer deposition on polymer fibers and fabrics for multifunctional and electronic textiles. Journal of Vacuum Science \& Technology A: Vacuum Surfaces and Films 34(1): 010801.

13. Xiao X, Cao G, Chen F, Tang Y, Liu X, et al. (2015) Durable superhydrophobic wool fabrics coating with nanoscale $\mathrm{Al}_{2} \mathrm{O}_{3}$ layer by atomic layer deposition. Applied Surface Science 349: 876-879.

14. Leskelä M, Ritala M (2003) Atomic layer deposition chemistry: recent developments and future challenges. Angew Chem Int Ed Engl 42(45): 5548-5554.

15. Xiao X, Liu X, Cao G, Zhang C, Xia L, et al. (2015) Atomic layer deposition $\mathrm{TiO}_{2} / \mathrm{Al}_{2} \mathrm{O}_{3}$ nanolayer of dyed polyamide/aramid blend fabric for high intensity UV light protection. Polymer Engineering and Science 55(6): 1296-1302.

16. Xiao X, Liu X, Chen F, Dong F, Zhang C, et al. (2015) Highly antiUV properties of silk fiber with uniform and conformal nanoscale $\mathrm{TiO}_{2}$ coatings via atomic layer deposition. ACS Applied Materials \& Interfaces 7(38): 21326-21333.

17. Roy AK, Schulze S, Hietschold M, Goedel WA (2012) Oxidation protection of carbon fibers by coating with alumina and/or titania using atomic layer deposition. Carbon 50(3): 761-770.

18. Roy AK, Baumann W, König I, Baumann G, Schulze S, et al. (2010) Atomic Layer Deposition (ALD) as a coating tool for reinforcing fibers. Anal Bioanal Chem 396(5): 1913-1919.

19. Chen F, Yang H, Liu X, Chen D, Xiao X, et al. (2016) Facile fabrication of multifunctional hybrid silk fabrics with controllable surface wettability and laundering durability. ACS Appl Mater Interfaces 8(8): 5653-5660.

20. George SM (2010) Atomic layer deposition: an overview. Chem Rev 110(1): 111-131.

21. Mundy JZ, Shafiefarhood A, Li F, Khan SA, Parsons GN (2016) Low temperature platinum atomic layer deposition on nylon-6 for highly conductive and catalytic fiber mats. Journal of Vacuum Science \& Technology A: Vacuum Surfaces and Films 34(1): 01A152. 
22. Guo HC, Ye E, Li Z, Han MY, Loh XJ (2017) Recent progress of atomic layer deposition on polymeric materials. Materials Science \& Engineering C: Materials for Biological Applications 70(Pt 2): 1182-1191.

23. Elam JW, Yanguas-Gil A, Libera JA (2017) Method and system for continuous atomic layer deposition. United States Patent, US 20150031157 A1.

24. Vähä-Nissi M, Sievänen J, Salo E, Heikkilä P, Kenttä E, et al. (2014) Atomic and molecular layer deposition for surface modification. Journal of Solid State Chemistry 214(3): 7-11.

25. Knez M (2007) Synthesis and surface engineering of complex nanostructures by atomic layer deposition. Advanced Materials 19(21): 3425-3438

26. Miao D, Hu H, Li A, Jiang S, Shang S (2015) Fabrication of porous and amorphous $\mathrm{TiO}_{2}$ thin films on flexible textile substrates. Ceramics International 41(7): 9177-9182.

27. Kayaoğlu BK, Göcek I, Kizil H, Trabzon L (2012) Functional nano and micro-scale thin film deposition on textiles: emerging technologies and applications. Journal of Textiles \& Engineers 19(88): 39-47.

28. Jur JS, Parsons GN (2012) Nanoscale ceramic surface modification of textiles by atomic layer deposition. American Ceramic Society Bulletin 91(6): 24-27.

29. Kalanyan B, Oldham CJ, Sweet WJ 3rd, Parsons GN (2013) Highly conductive and flexible nylon- 6 nonwoven fiber mats formed using tungsten atomic layer deposition. ACS Appl Mater Interfaces 5(11): 5253-5259.

30. Jur JS, Iii WJS, Oldham CJ, Parsons GN (2011) Atomic layer deposition of conductive coatings on cotton, paper, and synthetic fibers: conductivity analysis and functional chemical sensing using "all-fiber" capacitors. Advanced Functional Materials 21(11): 1993-2002.

31. Sweet W, Jur JS, Parsons GN (2011) Conductive coatings on nonwoven fiber mats by atomic layer deposition. AVS 58th Annual International Symposium and Exhibition.

32. Sarah E Atanasov, Christopher J Oldham, Kyle A Slusarski, Joshua Taggart-Scarff, Shalli A Sherman, et al. (2014) Improved cut-resistance of Kevlar@ using controlled interface reactions during atomic layer deposition of ultrathin $(<50 \AA)$ inorganic coatings. Journal of Materials Chemistry A 2(41): 17371-17379.

33. O’Brien S, Cosgrave L, Lodge V, Povey IM (2015) Atomic layer deposition on fabrics for flame resistance. ECS Transactions 66(40): 31-35.

34. Feldhoff A, Pippel E, Woltersdorf J (2000) Interface engineering of carbon fiber reinforced Mg-Al alloys. Adv Eng Mater 2(8): 471-480.

35. Pimenta S, Pinho ST (2011) Recycling carbon fiber reinforced polymers for structural applications: technology review and market outlook. Waste Manag 31(2): 378-392.

36. Helmer T, Peterlik H, Kromp K (1995) Coating of carbon fibers-the strength of the fibers. J Am Ceram Soc 78(1): 133-136.

37. Han KH, Ono H, Goto KS, Pierre GR St (1987) Rate of oxidation of carbon fiber/carbon matrix composites with antioxidation treatment at high temperature. J Electrochem Soc 134(4): 1003-1009.

38. Chen F, Yang H, Li Ke, Deng B, Li Q et al. (2017) Facile and effective coloration of dye-inert carbon fiber fabrics with tunable colours and excellent laundering durability. ACS Nano 11(10): 10330-10336.

39. Roy AK, Baumann W, Schulze S, Hietschold M, Mader T, et al. (2011) Atomic Layer Deposition of Alumina onto Carbon Fibers. J Am Ceram Soc 94(7): 2014-2022.

40. Abidin AZ, Kozera R, Höhn M, Endler I, Knaut M, et al. (2015) Preparation and characterization of CVD-TiN-coated carbon fibers for applications in metal matrix composites. Thin Solid Films 589(2): 479-486.

41. Roy AK, Wolfgang B, Steffen S, Michael H, Thomas M, et al. (2011) Atomic layer deposition of alumina onto carbon fibers. Journal of the American Ceramic Society 94(7): 2014-2022.

42. Militzer C, Dill P, Goedel WA (2017) Atomic layer deposition onto carbon fiber fabrics. Journal of the American Ceramic Society 100(12): 5409-5420.

43. Westwood ME, Webster JD, Day RJ, Hayes FH, Taylor R (1996) Oxidation Protection for Carbon Fibre Composites. Journal of Materials Science 31(6):1389-1397.

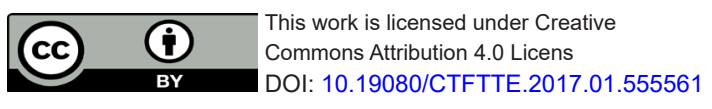

\begin{tabular}{|l|}
\hline \multicolumn{1}{|c|}{ Your next submission with Juniper Publishers } \\
will reach you the below assets \\
- Quality Editorial service \\
- Swift Peer Review \\
- Reprints availability \\
- E-prints Service \\
- Manuscript Podcast for convenient understanding \\
- Global attainment for your research \\
- Manuscript accessibility in different formats \\
( Pdf, E-pub, Full Text, Audio) \\
- Unceasing customer service \\
Track the below URL for one-step submission \\
https://juniperpublishers.com/online-submission.php \\
\hline
\end{tabular}

